\title{
Pakistani Women's Perceptions and Experiences of the Psychological Impact of Advanced Breast Cancer
}

\author{
Maggi Banning* \\ Senior Lecturer in the School of Health Sciences and Social Care, Brunel University, UK \\ *Corresponding author: Dr. Maggi Banning, Senior lecturer in the School of Health Sciences and Social Care, Brunel University, UK, Tel: 018952 68828; E-mail: \\ maggi.banning@brunel.ac.uk
}

Rec date: Apr 8, 2014, Acc date: July 16, 2014; Pub date: July 26, 2014

Copyright: (c) 2014 Banning M. This is an open-access article distributed under the terms of the Creative Commons Attribution License, which permits unrestricted use, distribution, and reproduction in any medium, provided the original author and source are credited.

\begin{abstract}
Background: Breast cancer is a common health problem in Pakistan. Due to limited breast health awareness, women often seek medical support when the disease is in an advanced stage. Breast cancer can be a frightening disease for women due to local beliefs about cancer and knowledge deficits.

Objectives:This study examined the psychological impact of a diagnosis of advanced breast cancer in Pakistani women. Setting/ Subjects; 21 women with a diagnosis of advanced breast cancer participated in interview.

Design: A qualitative study employing semi-structured interviews to explore women's perceptions and experiences of the psychological impact of their diagnosis on their lives. Women adopted religious coping strategies to manage the long-term manifestations of their disease and the seriousness of their diagnosis. Many women questioned their perceptions of the challenges that they faced; the meaning of life for them as mothers, wives and constant fear of recurrence and impact that this could have in their lives. Possessions and money were of little consequence to them as their existence and duration of life was perceived to be limited.
\end{abstract}

Conclusions: Many women revitalised their perceptions of the purpose of life and developed increased optimism for the future. This optimism was related to their renewed spirituality which they used as a coping strategy.

Keywords: Breast cancer; Psychological experience; Life goals; Spirituality; Qualitative

\section{Introduction}

Pakistan is a developing country where up to $70 \%$ of women present when breast cancer is in its advanced stage [1]. Advanced breast cancer is cancer that is metastatic [2].

Advanced breast cancer is a life threating disease with a poor prognosis profile [3]. Women with a diagnosis of advanced breast cancer engage in a multi-stage cancer treatment cycle often involving surgery, radiation treatment and chemotherapy. These cycles of treatment are not free of side effects. Women have to face possible disfigurement, surgical pain, the side effects from chemotherapy which can include feelings of anger, frustration, fear, isolation, fatigue as well as burns from targeted radiotherapy [4].

Evidence indicates that women with breast cancer find all stages of the illness trajectory stressful [5]. This is mainly due to the physical and emotional demands of the illness and the need to engage in, and recover from the repetitive cycles of chemotherapy and radiation treatment $[6,7]$. Fatigue and feelings of isolation, querulous anger and frustration are commonly reported symptoms following chemotherapy treatment [4]. During this time, stress levels possibly fluctuate in par with emotional well-being. This includes the psychological impact of their illness including managing the stress and emotions they may feel during all stages of the illness trajectory $[7,8]$.
Breast cancer is associated with a rollercoaster of emotions for women mainly because breasts are organs of femininity, motherhood, and sexual health but also because of the public negative impression of breast cancer $[9,10]$. Such impressions can have a tremendous impact on the psychological state of women and relationships with families, friends and local communities [11]. As a result of the psycho-social aspects of the disease and its influence on their families, many women question the reason for their disease and often turn to, and engage in, religious practices as a coping strategy to relieve or distract them from their illness particularly the psychological impact of living with the constant fear of recurrence, feelings that life is a "ticking time bomb" $[6,3]$.

Unfortunately in Pakistan, cancer is viewed negatively and is associated with impressions of contagion and impending death [10]. In Pakistan, there is a paucity of evidence on the lived experiences of women with advanced breast cancer. This is the first study to examine Pakistani women's views, perceptions and experiences of the psychological impact of living with advanced breast cancer.

\section{Methods}

The co-investigator identified suitable women attending the daily advanced breast cancer follow-up clinic. Potential participants were introduced to the study aims and what was involved. In total 75 women attended the clinic. Of these, 25 women declined to participate mostly due to shyness. Fifty women showed an interest in participating in the study, from these a purposive sample of 35 women was selected based on the following criteria; Pakistani National, aged 
Page 2 of 4

33-83 years, confirmed history of advanced breast cancer, completion of all forms of treatment, and receiving follow-up care as an outpatient. The ethics of participation was discussed individually with all women prior to interview particularly anonymity and confidentiality of data generated during interview. Women were given the preference of being interviewed in English or Urdu. The co-investigator is a clinical psychologist and Pakistani national who is employed by the hospital, she interviewed all women (TT). The demographic details of the sample are provided (Table 1). Semi-structured interviews were chosen as the preferred form of data collection due to the flexibility of the approach, the ability to generate rich descriptions of the data, prompting follow-up questioning and assisting the visualisation of common patterns of meaning through preliminary data analysis [12].

\begin{tabular}{|c|c|c|c|c|c|c|}
\hline $\begin{array}{l}\text { Patient } \\
\text { Number }\end{array}$ & Age in years & Marital status & Occupation & Number of children & Time since diagnosis & BC status \\
\hline 1 & 45 & Married & Housewife & 3 & 8 months & Metastases \\
\hline 2 & 51 & Married & Housewife & 4 & 2 years & Metastases \\
\hline 3 & 53 & Married & Housewife & 4 & 4 years & Adv. BC \\
\hline 4 & 50 & Married & Housewife & 7 & 2 years & Adv. BC \\
\hline 5 & 39 & Single & Housewife & 0 & 2 years & Metastases \\
\hline 6 & 67 & Married & Housewife & 5 & 4 years & Adv. BC \\
\hline 7 & 54 & Single & Teacher & 0 & 5 years & Metastases \\
\hline 8 & 54 & Married & Housewife & 3 & 1 year & Metastases \\
\hline 9 & 51 & Married & Housewife & 5 & 9 months & Metastases \\
\hline 10 & 35 & Married & Housewife & 5 & 8 months & Metastases \\
\hline 11 & 39 & Single & School teacher & 0 & 8 months & Metastases \\
\hline 12 & 42 & Single & School teacher & 0 & 12 months & Metastases \\
\hline 13 & 33 & Married & Policewoman & 0 & 6 months & Metastases \\
\hline 14 & 65 & Married & Housewife & 5 & 2 years & $A d v, B C$ \\
\hline 15 & 47 & Married & Housewife & 4 & 11 years & Metastases \\
\hline 16 & 42 & Married & Housewife & 5 & 5 years & Adv. BC \\
\hline 17 & 46 & Married & Housewife & 3 & 2 years & Metastases \\
\hline 18 & 49 & Married & Housewife & 4 & 18 months & Fungating $B C$ \\
\hline 19 & 65 & Married & Retired Politician & 5 & 5 years & Metastases \\
\hline 20 & 83 & Married & Housewife & 4 & 2 years & Metastases \\
\hline 21 & 41 & Married & Maid & 4 & 2 years & Metastases \\
\hline
\end{tabular}

Table 1: Demographic details of the sample of women

The themes and questions for the semi- structured interviews were developed from the available literature but were also informed by the professional, knowledge, and research experience of both investigators (MB, TT). The co-investigator (TT) has extensive experience of counselling cancer patients attending the hospital for treatment and follow-up. As a Pakistani national, (TT) provided advice on cultural sensitivity, cultural heritage and religious persuasion. Three pilot samples tested the suitability of the interview questions. Changes were made to interview schedule as necessary to ensure the consistency of the interview process and to enhance the validity and reliability of the data collected [13]. Questions included the following: When you found out that your disease was advanced, how did you react? What is keeping you motivated to cope with your illness? Has this disease changed your perception regarding life? What is the most important goal for you to achieve in life? Interviews were digitally recorded (TT). Iterative cycles of data collection and data analysis were undertaken this continued until data saturation occurred after 21 interviews [14]. At this time no new findings were emerging during interviews, therefore interviews were terminated.

The study setting was a private, fully functional, cancer hospital and research centre based in Lahore, Pakistan.

\section{Participants}

Women ranged from 33 to 83 years with differing levels of literacy. All women lived in Lahore and surrounding villages. All women had 
Page 3 of 4

completed all phases of cancer treatment and were receiving follow-up care. Fifteen women had a diagnosis of single site metastasis. Three women were single, and 18 women were married. During interview, the range of responses from women was fairly consistent and did not appear to be influenced by breast cancer type.

\section{Data Analysis}

Interviews were transcribed verbatim, analysed and coded using thematic analysis [13] Both reviewers (MB Researcher and TT) independently clustered responses from transcripts which were then compared, cross checked and differences were explored during theme development. Matrices were developed to illustrate the commonalities and presenting patterns of themes presenting in the data $[14,15]$. The research team further analysed the data for any ambiguity or biases as the final themes emerged from the data [14-16]. The selections of quotes were agreed by TT and MB as those supporting the emerging themes.

\section{Ethical Considerations}

Ethical approval was provided by the University Research Ethics Committee, and Shaukat Khanum Memorial Cancer Hospital \& Research Centre, Scientific Review Board and Institutional Review Board.

\section{Results}

Three themes emerged from the interviews. Quotations are provided to illustrate data informing the analysis. The three themes include: Adoption of religious coping; meaning of life following cancer and the insecurity of health.

\section{Adoption of religious coping}

Women used religious coping as a strategy to manage the devastating impact of their diagnosis, constant fear of recurrence. Women also had to contend with the psychological, social and cultural significance of the disease but also the impact of their diagnosis on immediate and extended family members and in some cases, the local community. Women sought psychological solace by engaging deferentially in religious practices; engaging in daily prayers, reading the Holy Koran, religious literature, visiting Holy sites of worship and participating in the Hajj pilgrimage. The following extracts illustrate the significance of these views:

"My religious beliefs have changed. For months I was unable to move, and then I started praying more, all my family members state that Allah has helped me, as my daughter is not fine and my gran daughters were at home alone, Allah has given me strength to look after them".

Women also viewed religious coping as a predominately positive experience they could engage in to promote and enhance their health and well-being.

"I have become stronger and I believe that I have received Allah's blessing. I am content after reading religious books and I became motivated especially after reading the words of the Koran".

\section{Meaning of life following cancer}

Many women addressed their feelings and notions of the meaning of life and how it had dramatically changed, particularly their maternal responsibility. This fear stems from the role of matriarch of the family with duties and responsibility for caring for the lives of their children and maintaining the household.

"I want to perform Islamic rituals. I want to get my children married and do something good for my final life".

For unmarried women, the absence of a supportive spouse and the devastating and continuous threat of cancer recurrence may have been detrimental to their future goals.

"I used to think that I would teach my nephews and nieces but as I have come to know my disease, I don't think about anything and I have no goals".

\section{The insecurity of health}

Many women expressed their anxieties related to the outcome of exploratory medical scans searching for recurrent metastatic growth. Women acknowledged how terrifying this was for them. Recurrence was always a murky shadow that influenced their life and that of their families. For some women the uncertainty of life was shrouded by the perception that life would be short and therefore the finality of, and concerns for the future may be futile.

"My perception has changed. I used to do a job and save money from my home. Now I am ill, I think when I die my money is in the bank and who will have that money? So now I use everything and buy things and don't save money. I spend money on myself, I don't have a big need to save it".

\section{Discussion}

In Pakistan, women are often uneducated with limited financial and educational resources. This can have an impact on their comprehension of the disease trajectory, treatment cycles and possible recurrence. Such deficiencies can leave women feeling subdued and depressed about living with the constant fear of uncertainty, recurrence with fear for both themselves and their children [17]. During this time, women can find that stress levels possibly fluctuate in par with emotional well-being. The fear of recurrence and also fears and concerns related to their finality of life. Many women acknowledged the issue of living with uncertainty was an impending death ticking time bomb (3). In such cases, many women revitalise their perceptions of the purpose of life and developed increased optimism for the future [18-20]. This may involve a renewal of the importance of their religious beliefs and spirituality [10].

Spirituality can be viewed as an existential but also a personal phenomenon [21]. It is quite common for cancer patients to acknowledge their connection and association with God and engage in religious based coping as a means to adjust to, and manage their illness trajectory $[4,22,23]$. This adjustment can involve the use of both behavioural and cognitive measures to manage life events they find stressful $[5,6,24]$. Health care professionals managing the care of breast cancer patients should provide holistic care that includes the recognition of the importance of religious empowerment for cancer patient [25].

In Pakistan, even though the incidence of breast cancer is increasing, breast health awareness is limited particularly among 
economically deprived and illiterate women. There is a need to recognise that breast cancer is a public health issue that needs to be addressed. Breast health awareness initiatives can aim to educate women and reduce the number of women being diagnosed with advanced breast cancer.

\section{Conclusions}

Women with advanced breast cancer recognised that their stress levels had a tendency to fluctuate in par with their emotional wellbeing. The fear of cancer recurrence and living with uncertainty was high amongst women. This fear impacted on both their family and individual perception of the purpose of life. Some women revitalised their perceptions of life and developed increased optimism for the future. The religious significance of illness is mediated through increased spirituality. Women discussed how they had reconnected with their faith and used this as a coping strategy to assist their adjustment to their illness.

\section{Acknowledgements}

This study would not have been possible without the engagement of the breast cancer patients at Shaukat Khanum Memorial Cancer Hospital. Your support and contributions are immeasurable and much appreciated. This project was funded by a grant from the British academy.

\section{References}

1. Bhurgri Y, Bhurgri A, Nishter S, Ahmed A, Usman A, et al. (2006) Pakistan--country profile of cancer and cancer control 1995-2004. J Pak Med Assoc 56: 124-130.

2. Definition of advanced breast cancer (2013) Advanced breast cancer community.

3. Davies M, Sque M (2002) Living on the outside looking in: a theory of living with advanced breast cancer. Int J Palliat Nurs 8: 583-590.

4. Banning M, Hafeez H, Faisal S, Hassan M, Zafar A (2009) The impact of culture and sociological and psychological issues on Muslim patients with breast cancer in Pakistan. Cancer Nurs 32: 317-324.

5. Zabora J, BrintzenhofeSzoc K, Curbow B, Hooker C, Piantadosi S (2001) The prevalence of psychological distress by cancer site. Psychooncology 10: $19-28$.

6. Gall TL, Guirguis-Younger M, Charbonneau C, Florack P (2009) The trajectory of religious coping across time in response to the diagnosis of breast cancer. Psychooncology 18: 1165-1178.

7. Longman AJ, Braden CJ, Mishel MH (1999) Side-effects burden, psychological adjustment, and life quality in women with breast cancer: pattern of association over time. Oncol Nurs Forum 26: 909-915.
8. Cordova MJ, Andrykowski MA, Kenady DE, McGrath PC, Sloan DA, et al. (1995) Frequency and correlates of posttraumatic-stress-disorder-like symptoms after treatment for breast cancer. J Consult Clin Psychol 63: 981-986.

9. Miller DL, Manne SL, Taylor K, Keates J, Dougherty J (1996) Psychological distress and well-being in advanced cancer: The effects of optimism and coping. J Clin Psychol Med Settings 3: 115-130.

10. Banning $M$, Tanzeem $T$ (2013) Managing the illness experience of women with advanced breast cancer: hopes and fears of cancer-related insecurity. Eur J Cancer Care (Engl) 22: 253-260.

11. Donovan-Kicken E, Caughlin JP (2011) Breast cancer patients' topic avoidance and psychological distress: the mediating role of coping. J Health Psychol 16: 596-606.

12. Grbich C (2007) Qualitative Data Analysis. Sage Publications.

13. Braun V, Clarke E (2006) Using thematic analysis in psychology. Qualitative Health Research 3: 77-101.

14. Flick U (2009) An Introduction to Qualitative Research. London: Sage Publications.

15. Miles M, Huberman M (1994) Qualitative data analysis: An expanded source book. London: Sage.

16. Morse JM, Barrett M, Mayan M, Olson K (2002) Verification strategies for establishing reliability and validity in qualitative research. Inter. J. Qualitative Methods 12: 13-22.

17. Banning M, Hassan M, Faisal S, Hafeez H (2010) Cultural interrelationships and the lived experience of Pakistani breast cancer patients. Eur J Oncol Nurs 14: 304-309.

18. Heim E, Augustiny KF, Schaffner L, Valach L (1993) Coping with breast cancer over time and situation. J Psychosom Res 37: 523-542.

19. Greisinger AJ, Lorimor RJ, Aday LA, Winn RJ, Baile WF (1997) Terminally ill cancer patients. Their most important concerns. Cancer Pract 5: 147-154.

20. Thuné-Boyle IC, Stygall J, Keshtgar MR, Davidson TI, Newman SP (2011) Religious coping strategies in patients diagnosed with breast cancer in the UK. Psychooncology 20: 771-782.

21. Stefanek M, McDonald PG, Hess SA (2005) Religion, spirituality and cancer: current status and methodological challenges. Psychooncology 14: $450-463$.

22. Woods TE, Ironson GH (1999) Religion and Spirituality in the Face of Illness: How Cancer, Cardiac, and HIV Patients Describe their Spirituality/Religiosity. J Health Psychol 4: 393-412.

23. Zwingmann C, Wirtz M, Müller C, Körber J, Murken S (2006) Positive and negative religious coping in German breast cancer patients. J Behav Med 29: 533-547.

24. Tix AP, Frazier PA (1998) The use of religious coping during stressful life events: main effects, moderation, and mediation. J Consult Clin Psychol 66: 411-422.

25. Clinical Standards of working in a breast speciality (2007) RCN Guidance for nursing staff. 